\title{
Produtivismo acadêmico e decorrências às condições de vida/trabalho de pesquisadores brasileiros e europeus
}

Lucídio Bianchetti* Ione Ribeiro Valle**

\section{Resumo}

Uma versão deste trabalho foi apresentada no $25^{\circ}$ Simpósio Brasileiro e $2^{\mathrm{o}}$ Congresso Ibero-Americano de Política e Administração da Educação, 2011, na PUC/SP. O texto resulta de pesquisa com 74 Coordenadores de Programas e Orientadores vinculados a Programas de Pós-graduação stricto sensu avaliados pela CAPES e com 16 investigadores ligados a universidades da União Européia, após a adesão destas ao "Pacto de Bolonha". Traz manifestações destes profissionais sobre as mudanças recentes a que as universidades foram submetidas, transformações que no seu processo e resultado, levaram àquilo que se vem denominando "Produtivismo Acadêmico", com consequências para a qualidade das produções intelectuais/acadêmicas e para a vida institucional e pessoal dos profissionais que se dedicam ao ensino e à pesquisa na graduação e na pós-graduação.

Palavras-chave: Produtivismo. Trabalho e Educação. CAPES. Processo de Bolonha.

\section{Introdução: O modelo CAPES e o Processo de Bolonha em tela}

\subsection{O modelo CAPES}

A história da pós-graduação (PG) stricto sensu, assim como a do ensino superior $^{1}$ brasileiro, é bastante recente. No Brasil, a PG teve seu processo de institucionalização iniciado nos primeiros anos da década de 1950 com a criação

\footnotetext{
Doutor em História e Filosofia da Educação (PUC/SP). Professor no Centro de Ciências da Educação da Universidade Federal de Santa Catarina (UFSC) e Bolsista de Produtividade em Pesquisa do CNPq. E-mail: lucidio.bianchetti@pq.cnpq.br.

** Doutora em Ciências da Educação,Université René Descartes, PARIS V, Sorbonne. Professora do Centro de Ciências da Educação da Universidade Federal de Santa Catarina (UFSC) e Bolsista de Produtividade em pesquisa do CNPq. E-mail: ione.valle@pq.cnpq.br / ionevalle@ced.ufsc.br.

1 Neste aspecto particular do ensino superior, uma vez que as primeiras e vacilantes iniciativas foram tomadas em solo brasileiro, com a chegada da família real em 1808, há um contraste gritante se comparado com o quase milenar histórico das universidades européias e aos quase 500 anos das primeiras universidades na América Espanhola.
} 
da Coordenação de Aperfeiçoamento de Pessoal de Nível Superior (CAPES). Esta iniciativa governamental inscreve-se no quadro das políticas de desenvolvimento adotadas no Brasil pelo Governo Juscelino Kubistchek (1956-1961). Trata-se de uma estratégia que visa a tornar o Brasil um grande país, afinal, "o trabalho científico está ligado ao curso do progresso", diria Max Weber (1864-1920) ao refletir sobre a ciência como vocação, e ao perguntar: "qual o significado da ciência no contexto da vida humana e qual o seu valor?" (WEBER, s/d p. 32). E é nesta ambiência que, após muitas disputas, é aprovada a primeira Lei de Diretirzes e Bases da Educação (LDB), de n. 4.024 de 1961.

Embora a CAPES tenha sido criada na década de 1950, é somente após o golpe militar (de 1964) e, sobretudo, a partir da elaboração dos Planos Nacionais de PG (o $1^{\circ}$ é de 1975), que este órgão foi implementado, contando com o apoio de parte da Comunidade Científica. Esta passou a participar da elaboração das políticas, por meio das Associações Nacionais de Pós-graduação - criadas, em sua maioria, de maneira induzida pela CAPES (BIANCHETTI, 2009a; SAVIANI, 2012) -, as quais passaram a indicar membros para formar os Comitês de apoio à elaboração de políticas educacionais e científico-tecnológicas para as áreas, à distribuição de bolsas e, principalmente, visando a compor comissões de avaliação desses Programas.

Inicialmente, a prioridade da CAPES era apoiar a formação de professores, no Brasil ou no exterior, para a atuação no ensino superior, especialmente nas universidades públicas. A criação da PG integra o conjunto de medidas voltadas à expansão e qualificação do ensino superior no Brasil, que, em meados dos anos 1950, era bastante incipiente. Anísio Teixeira (1900-1971), um dos fundadores da CAPES e seu secretário por mais de 15 anos, pretendia, por meio da instituicionalização da PG, "reconstruir a universidade brasileira" (MENDONÇA, 2003, p. 301), objetivos ratificados por Ribeiro (1969) em anos posteriores ao explicitar sua concepção de universidade no contexto de criação da Universidade de Brasília. Podemos dizer que, a exemplo da organização do ensino superior, a PG brasileira também é criada e se expande com fortes influências estrangeiras, a ponto de Lüdke (2005), explicitar que nossa PG referindo-se à da Educação em especial - é resultado de "influências cruzadas", tanto na constituição quanto na expansão, particularmente advindas da França e dos EUA.

$\mathrm{Na}$ especificidade da área de Educação, o primeiro curso de $\mathrm{PG}$ - o mestrado em educação-foi criado na Pontifícia Universidade Católica do Rio de Janeiro (PUC-Rio) em 1965 (CURY, 2005). No entanto, somente 11 anos depois são criados os primeiros 
dois cursos de doutorado, um deles em 1976, na PUC-Rio e outro na Universidade Federal do Rio Grande do Sul (UFRGS), o que evidencia o caráter tardio do surgimento da PG stricto sensu no Brasil. Destaque-se o fato de serem universidades confessionais as pioneiras no campo da PG stricto sensu (SAVIANI, 2012). Porém, é a partir dos anos de 1970 que os Programas de PG ganham forte impulso, especialmente nas universidades públicas e confessionais, uma vez que o ensino superior privado, naquele momento, não havia alcançado, no nível da PG, a explosão que experimentaria em anos mais recentes.

A educação formal brasileira, como um todo, expandiu-se de uma maneira sem precedentes a partir da queda do regime ditatorial e da retomada do processo democrático, o que ocorreu pela institucionalização da chamada Nova República, em 1985, e da aprovação de uma nova Constituição Federal para o país (1988) e de uma nova lei para a educação brasileira (a LDBEN n. 9394/96). Foi nesse contexto de expansão que, em meados dos anos de 1990, os Programas de PG passaram a ser submetidos, na sua forma de gestão, avaliação e financiamento (BIANCHETTI, 2009a), a mudanças profundas, de caráter indutivo, que afetaram os pesquisadores e a própria qualidade da produção do conhecimento.

Entre essas mudanças, destacam-se:

a) a redução do tempo para conclusão das dissertações e teses (dois e quatro anos, respectivamente). Uma das decorrências ${ }^{2}$ desse aligeiramento refletiu-se na qualidade das pesquisas realizadas nesse nível de ensino (KUENZER; MORAES, 2005);

b) a submissão de todas as áreas do conhecimento, independentemente das demandas metodológicas e do perfil epistemológico de cada uma delas e de todo o país, a um mesmo padrão de avaliação, apesar da heterogeneidade que caracteriza as diferentes regiões de um país com as dimensões continentais como o Brasil;

c) a transformação dos cursos em Programas, na busca de garantir uma maior organicidade entre o mestrado e o doutorado, bem como a melhoria da vinculação entre a graduação e a pós-graduação (CURY, 2004);

2 Falamos em "uma das decorrências" dado que outros aspectos negativos e positivos devem ser arrolados como resultantes dessa medida de constrição do tempo para concluir os cursos de pós-graduação. Entre os aspectos positivos pode-se destacar o aprimoramento e qualificação no recorte das temáticas de pesquisa; a diminuição da evasão de pós-graduandos dos Programas, decorrendo daí diminuição de gastos públicos e ampliação no número de mestrandos e doutorandos, subsidiados com bolsas de estudo. Para um aprofundamento nesta questão dos aspectos negativos e outros que não deixaram tanto a desejar, como resultado da diminuição do tempo para concluir a pós-graduação, cf. Bianchetti (2009b). 
d) a submissão do financiamento à avaliação (trienal), com previsão de recompensas ou punições em termos do número de bolsas e do valor das taxas de auxílio, descaracterizando o próprio conceito de avaliação (SGUISSARDI, 2009);

e) a mudança nos objetivos da CAPES: da formação de professores para o ensino superior à formação de pesquisadores. As mudanças foram avaliadas como transformações que interferiram fortemente na dinâmica da PG, a ponto de poder-se afirmar que o Sistema CAPES de avaliação e fomento, provocou uma verdadeira mudança paradigmática, conforme Kuenzer e Moraes (2005) na PG brasileira;

f) Cabe destacar também, embora resulte de decisões mais recentes, a ampliação do espectro de atuação da CAPES, a partir da assunção, por parte da Fundação, da formação de professores da Educação Básica (Diretoria da Educação Básica). Se de um lado é bem-vinda a iniciativa de reforçar a Educação Básica (EB), de qualificar a relação entre a $\mathrm{PG}$ e a EB, de outro preocupa a abertura do leque de responsabilidades da CAPES, no sentido de assegurar que o acréscimo orçamentário acompanhe as novas frentes que demandam financiamento.

Se de um lado o período de surgimento da PG é recente e submetida a transformações que colocam todos os envolvidos sob pressão, de outro não se pode deixar de reconhecer que o Sistema é considerado um sucesso, principalmente do ponto de vista dos gestores governamentais, que atribuem à pesquisa gerada nos Programas PG a condição de o Brasil ter ultrapassado os $2 \%$ na produção da ciência mundial, e o país ter alcançado a $13^{\mathrm{a}}$ posição no ranking dos países produtores de ciência. E citam os números que reforçam este otimismo: mais de 40 mil mestres e 10 mil doutores formados ao ano, mais de quatro (4) mil cursos de PG avaliados e financiados pela CAPES (a área de Educação, por exemplo, ultrapassou a barreira dos 100 cursos/programas). Como afirma Ribeiro (2008), ex-diretor de Avaliação da CAPES, o "modelo CAPES" tem-se transformado em um 'produto' de exportação, particularmente para países do Terceiro Mundo.

\subsection{O Processo de Bolonha: um antídoto ao ‘imobilismo' da Universidade?}

No que diz respeito ao "Processo de Bolonha" ou "Pacto" ou também "Declaração de Bolonha", assinada conjuntamente pelos ministros da educação dos países da 
União Europeia (UE) em 19 de Junho de $1999^{3}$, não nos estamos referindo a um ponto zero do ensino superior europeu. Medidas vinham sendo tomadas, visando ao considerado necessário aggiornamento da universidade e sua convocação para contribuir com o ingresso da Europa na competitiva sociedade e economia do conhecimento (BINDÉ, 2007). A Magna Charta Universitatum (do ano de 1988) pode ser considerada uma ou talvez a última reação dos reitores a um olhar e ações pragmáticas e utilitárias na direção da Universidade. Daí por diante, os reitores vieram perdendo o protagonismo e a autonomia foi rapidamente sendo atingida em um dos elementos mais caros da sua instituição e funcionamento: a autonomia. A "Declaração da Sorbone" (do ano de 1998) passou a deixar clara a entrada em cena dos governos, via ministros da educação, numa postura ambivalente entre preservar a Instituição e exigir dela agilidade e retornos mais concretos aos investimentos nela feitos. De outra parte, Programas já haviam sido desencadeados anteriormente (o Erasmus ${ }^{4}$, por exemplo) e outros passaram a ser implementados, visando a promover e a incentivar a mobilidade, o intercâmbio de alunos da graduação e, mais recentemente, da PG e docentes das universidades.

"Área Europeia de educação superior”, "Área de integração do conhecimento", "Espaço europeu de educação superior", "Europa do conhecimento", são algumas das expressões que evidenciam a centralidade da educação ou de como o "conhecimento passa a constituir a pedra-de-toque" (SIMÃO et al, 2005) deste novo tempo e espaço ocupado pela educação no âmbito da UE. Conforme analisam estes autores, a Declaração de Bolonha, subscrita em 1999 pelos Ministros da Educação de 29 países europeus e presentemente adotada por $47^{5}$ países,

tem como objectivo a construção, num horizonte temporal de dez anos, de um "Espaço Europeu de Ensino Superior" (EEES) coeso, harmônico, competitivo e atractivo, com a finalidade

3 À reunião inicial, que deu origem à "Declaração de Bolonha", seguiu-se a definição, por parte dos ministros da educação dos países que aderiram ao "Pacto", de, a cada dois anos, voltarem a reunir-se para avaliar e projetar as metas do "Plano". À reunião inicial seguiram-se as bienais de: Praga, em 2001; Berlim, em 2003; Bergen, em 2005, Londres, em 2007, Leuven/Louvain-la-Neuve, em 2009 e Budapeste e Viena, 2010. Em 2012 já está agendada a próxima reunião, em Bucareste.

4 Acrônimo de: European Action Scheme for the Mobility of University Students. No contexto da globalização e da internacionalização da educação, Erasmus foi um Programa criado pela União Europeia, para, via educação, potencializar a mobilidade dos estudantes (hoje abrange docentes também), a integração e a identidade europeias, entre outros aspectos. Mais recentemente o Programa passou a ser considerado uma das peças para a constituição do Espaço Europeu de Educação Superior (EEES).

5 Há países que, mesmo não tendo sido aceitos ou aderidos à União Européia, adotaram o "Processo de Bolonha" como estratégia de organização e funcionamento de suas universidades. E há, inclusive, universidades de países de fora do Continente Europeu, que na parte ou no todo adotaram o "Sistema Bolonha" em universidades. O texto de Adelman (2008) é muito ilustrativo a este respeito. 
genérica de promover a mobilidade dos estudantes e demais agentes educativos e a empregabilidade dos diplomados, por forma a dar conteúdo real aos direitos de livre circulação e estabelecimento dos cidadãos, e de reforçar a competitividade internacional do ensino superior europeu no contexto da crescente globalização dos sistemas de ensino e formação. (SIMÃO et al, 2005 p. 40) (destaque nosso).

Para Dias Sobrinho (2009, p. 135), "uma das maneiras de atrair mais matrículas estrangeiras é conciliar no sistema as ideias de comparabilidade e compatibilidade com as de flexibilidade e diversidade institucional". Desencadeado esse processo, o objetivo da mobilidade passa a ser passível de ser alcançado. Nessa perspectiva é que se discutee se implementa o European Credit Transfer System (ECTS), um "sistema Europeu de Créditos Transferíveis, uma espécie de 'moeda única' da educação superior da Comunidade Europeia" (ID.,p. 137), apontando à ideia de 'monetarização' a que a palavra 'crédito' remete (CARRERAS GARCÍA et al, 2006).

O que chama a atenção é o fato de que, na década de 1950, quando foram dados os primeiros passos para a criação da Comunidade Europeia, com a assinatura dos acordos firmados por seis países, com questões relacionadas à derrubada de barreiras comerciais, à necessidade de refrear a produção e proliferação de armas atômicas, etc., "la educación no jugaba ningún papel" (RUIZ, 2004, p. 24). Nos dias atuais, diferentemente, a educação, pelo menos no discurso, 'joga' no centro da cena. Ruiz, ao analisar a mudança de um período para outro, destaca: "no es arriesgado señalar que ésta es la iniciativa más importante que Europa há desarrollado en el área de la Educación Superior en los últimos cien años" (RUIZ, 2004, p. 32).

Documentos relacionados ao Processo de Bolonha previam o ano de 2010 como limite à uniformização dos sistemas de educação de cada país da UE, convergindo em ciclos que se materializam em três anos de graduação, dois de mestrado e três para o doutorado. Segundo esses documentos orientadores, seria o alcance desta meta que garantiria "a flexibilidade dos percursos de formação", isto é, a "mobilidade dos estudantes" que, juntamente com a "empregabilidade dos diplomados" e o reforço à "competitividade internacional", formam o tripé no

6 A preocupação com a competitividade internacional aparece explicitamente com muita freqüência, quer no documento original de Bolonha, quer nas análises feitas sobre ele, que vão de um viés crítico (SERRALHEIRO et al, 2005; RUIZ, 2004), a um apologético (SIMÃO et al, 2005). Neste, é explicitado claramente esse aspecto: "[...] o modelo europeu de desenvolvimento poderá ganhar uma vantagem comparativa em relação aos Estados Unidos da América e atenuar conseqüentemente o diferencial competitivo existente" (p. 29). 
qual se assentam as principais proposições de Bolonha (SIMÃO et al, 2005). Apreender que há formas diversas de analisar a suposta globalização e seu presumido caráter de novidade permite avançar para especificidades que ajudam a entender o quanto essa característica, reconhecidamente inerente ao sistema vigente, abrange, interfere, impacta e direciona as outras instâncias da sociedade, bem como os indivíduos em particular, para além do econômico, em especial, no que diz respeito à educação. Em outras palavras, em que medida essa globalização que traz desde o seu nascedouro e na sua materialização as marcas do sistema vigente - que desconhece fronteiras geográficas - se faz presente e determina a forma de ser e de agir da instituição universidade, nela inoculando e tornando operacional a lógica de mercado? Quais são as estratégias utilizadas para colocar em marcha o chamado processo de "internacionalização da educação" (MOROSINI, 2008), rumo ao apontado por Moraes (2006) ao analisar o processo de "globalização de um modelo de ensino superior", referindo-se à Declaração de Bolonha ou àquilo que Sguissardi (2005) denomina de "a universidade mundial do banco mundial"? Como se traduzem no interior da universidade as regras que são próprias ao sistema vigente, na organização dos currículos, na pesquisa, na produção do conhecimento, na relação e na gestão entre e intrainstitucional; na relação desta instituição com o seu entorno; na relação entre pares e particularmente na avaliação (processo/produto) do ser/fazer dos pesquisadores?

Para a especificidade daquilo que nos interessa neste trabalho, contudo, há uma convergência: desloca-se o polo do ensino para a aprendizagem; do foco do professor, passa-se a apostar na autonomia do aluno e aquele deve ficar à disposição deste, mais na condição de tutor ${ }^{7}$ do que de professor.

\section{As pesquisas}

Por meio de pesquisas iniciadas em 2003, investigamos as modalidades e estratégias de orientação utilizadas por orientadores, suas concepções dessa função, os problemas enfrentados no seu exercício e as soluções que foram sendo encontradas e implementadas, incluindo as mudanças que perceberam na sua trajetória (de orientando a orientador) e as explicitações para a resistência e/ ou desistência dos pós-graduandos frente à elaboração das teses e dissertações. Igualmente, mapeamos iniciativas e estratégias desencadeadas por Coordenadores e professores da PG em Educação a partir das novas regras estabelecidas pela

7 Conforme Carreras García (2006, p. 66) "o profesorado (fica) reducido a labores de asistencia y tutoría del alumnado pues la mera emissión de información queda reservada a las nuevas tecnologías". 
CAPES, na busca de soluções para a equação: manutenção da qualidade das dissertações e teses, contando com menos tempo e menos recursos. Os dados das pesquisas foram colhidos junto a 74 Orientadores e Coordenadores de Programas de Pós-graduação em Educação no Brasil. A escolha recaiu sobre aqueles avaliados com notas 5 e 6 , uma vez, que no período abrangido pela pesquisa, não havia Programas com avaliação superior a 6, numa escala que vai de 3 a 7. O critério para escolhermos Programas com notas mais elevadas tem a ver com a suposição de que estes se adaptaram mais adequadamente às regras de avaliação e ao financiamento do Sistema.

Um aspecto que ganhou espaço e intensidade nas entrevistas foram as decorrências dessas mudanças para a produção do conhecimento e as condições de vida desses pesquisadores. Esse fato levou-nos a realizar mais duas pesquisas, uma delas entre 2007 e 2010 - financiada pelo CNPq para aprofundar os dados coletados anteriormente - e outra em 2009, sobre as estratégias que os pesquisadores estão desenvolvendo para lidar com a intensificação e a extensão da jornada de trabalho. Na pesquisa de 2009 - decorrente de estágio pós-doutoral - fizemos entrevistas com 16 pesquisadores europeus, envolvidos com a implementação do Processo de Bolonha, atuando em seis diferentes universidades e ligados a diversas áreas do conhecimento. Interessava-nos investigar como as novas exigências à PG instituídas no Brasil pelo Sistema CAPES e na União Europeia (2ํㅜ e $3^{\circ}$ Ciclos) pelo Processo de Bolonha - estavam impactando a produção, a veiculação do conhecimento e a vida desses pesquisadores. Esse estudo comparado (NÓVOA, 2009; SOUZA; MARTÍNEZ, 2009), justificava-se em função da abrangência que o Modelo CAPES de avaliação adquiriu e o quanto o Processo de Bolonha se tornou um paradigma, um modelo em processo de globalização, como afirmam (ROBERTSON, 2009; LIMA et al, 2008).

\section{Decorrências do(s) modelo(s): O produtivismo em questão}

Como apontamos anteriormente, as influências anglo-saxã e a francófona, na história da educação brasileira, são inegáveis. De todo o leque destas, porém, não há como deixar de reconhecer que uma das mais determinantes e visíveis é aquela que decorre da política sintetizada na fórmula "publish or perish" (publique ou pereça), oriunda dos EUA e que passou a ser uma das mais influentes no novo patamar a que foi induzida a PG brasileira, e porque não dizer, mundial. Nos 
EUA, particularmente, dois autores (JACOBY, 2001; WATERS, 2006) tratam das consequências nefastas dessa política implementada nos campi, seja para os pesquisadores, seja para suas produções.

No Brasil, as mudanças atingem não apenas as instituições universitárias, mas também repercutem junto aos Coordenadores de Programas, aos professores e aos pós-graduandos, que são compelidos a se preocupar com índices, classificações, fatores de impacto, rankings e, principalmente, a lidar com situações que envolvem um grande grau de competição entre os Programas. Estudos (HESS, 2005; WATERS, 2006; NERAD; HEGGELUND, 2008; BIANCHETTI, 2010) permitem apontar que esta é uma tendência mundial, no contexto descrito por Slaughter e Rhoades (2004) e Paraskeva (2009) como "Academic Capitalism".

Entre as principais decorrências do predomínio desses modelos, destacamos a predominância do quantitativo sobre o qualitativo, que interfere na produção científica e gera o que é denominado por "produtivismo acadêmico" (SGUISSARDI; SILVA JUNIOR, 2009; BIANCHETTI, 2009a). De outra parte, constatamos um descontentamento e um desconforto com a interferência que essa aceleração provoca na produção acadêmica, uma vez que atinge diretamente a qualidade da formação de novos pesquisadores. Estes são forçados a "trocar o livro pelo paper", como diz Chaú (2003) ou a utilizarem "artimanhas" para dar conta dos índices de produtividade exigidos ou, no limite, a cometerem "imposturas intelectuais" (SOKAL; BRICMONT, 1999), inflando a produção científica", conforme reportagem da Folha de S. Paulo (RIGHETTI, 2010).

Este quadro de descontentamento está relacionado também às condições de trabalho. Segundo um dos nossos entrevistados,

os pesquisados brasileiros e europeus estão submetidos a condições de trabalho similares, sejam professores, orientadores ou pesquisadores. Ainda que os pesquisadores brasileiros tenham tido que enfrentar a pressão antes que seus colegas europeus (refiro-me ao fato de a CAPES ter arrochado a partir de meados da década de 1990 enquanto os europeus passaram a sentir mais a pressão após a implementação de Bolonha), ambos os grupos estão agora em situações parecidas. Todos eles precisam dar aulas, conduzir pesquisas, orientar estudantes, escrever papers, participar de conferências, publicar. 
Uma das questões que tem sido objeto de críticas e de importantes reações diz respeito à categoria 'tempo' e ao seu redimensionamento no trabalho acadêmico. As mudanças concernentes a essa categoria afetam os pesquisadores de diferentes formas: tanto no aspecto institucional dos Programas - trabalho de orientação com a redução do tempo dos mestrados e doutorados - quanto na produção do conhecimento. Nos seus estudos, Hess (2005, p. 25) analisa a redução do tempo de realização dos cursos: "os estudantes [franceses] não devem ultrapassar três ou quatro anos para fazer sua tese, e os orientadores não podem mais receber sob sua direção mais que um número limitado de estudantes, qualquer que seja sua disciplina". Com relação à produção acadêmica, os depoimentos dos entrevistados evidenciam o comprometimento da qualidade do que é produzido pela pressão de publicar: "tornamo-nos especialistas em amontoar fragmentos"; "requentamos diferentes versões do mesmo texto". Igualmente, apontam a interferência destas exigências produtivas na sua qualidade de vida: assinalam que afeta seu lazer e seu descanso. Exemplar neste aspecto é a afirmação de uma das entrevistadas brasileira: "estamos vivendo um tempo em que o sábado ainda é sexta-feira e o domingo já é segunda-feira".

Há concordância que a globalização das tecnologias digitais - embora com ritmos e abrangências diferenciadas - contribuiu para encurtar distâncias, abreviar tempos e provocando uma série de vantagens relativas ao acesso à base de dados, a possibilidades de orientação a distância, à disponibilidade de softwares sofisticados para tratamento dos dados de pesquisa. Paralelamente, denuncia-se o quanto essas estratégias possibilitam a invasão do espaço-tempo dos orientadores e interferem na sua vida e no seu trabalho, pois passam a ser solicitados "em qualquer hora e lugar". Sobre este aspecto, um dos entrevistados, pesquisador espanhol, assim descreve:

O tempo é muito mais denso e intenso e a impressão que se tem é de que o tempo escapa e de não fazermos bem o próprio trabalho por falta de tempo. Esta impressão é cada vez mais forte (...). O computador, em casa, permite teletrabalhar de dia e de noite, fazer mais trabalhos e trabalhar mais e melhor, porém com custos à qualidade de vida pessoal.

E para reforçar o seu ponto de vista, acrescenta um exemplo relacionado à sua experiência pessoal como orientador: "agora estou orientando muitas teses online. 
Quer dizer que as quatro da tarde me chega um e-mail com arquivo e, às oito da noite, chega-me outro $e$-mail me perguntando: "Você leu"? "Mas você, contudo, não me respondeu!?".

Da mesma forma, um pesquisador brasileiro destaca como a intensificação do trabalho está gerando a competitividade entre pesquisadores e instituições de pós-graduação:

A gente é prisioneira de uma temporalidade, prisioneira de uma produtividade, prisioneira de um fluxo, e aquilo que é o próprio exercício da construção teórica, da construção do pensamento, que tem totalmente outro tempo, porque é o tempo da criação, hoje em dia isso não existe. (...) Estamos submetidos a uma política duríssima. A guerra da produtividade...

As críticas presentes nos depoimentos convergem para o entendimento de que a pressão pela produtividade provoca distorções que parecem atentar contra a tradição histórica da universidade. Ao analisar esta questão Hess (2005, p. 61), entende que se trata "de uma mudança sócio-histórica da instituição que transformou o trabalho do orientador" e que faz com que a realização de um mestrado se torne uma verdadeira corrida de obstáculos, pois está centrada exclusivamente em resultados imediatos. Nessa mesma perspectiva, Chauí (2003) alerta para o fato de que a universidade vem perdendo sua característica de instituição na direção de transformar-se em uma organização, onde há o primado do produtivismo como qualquer outra organização mercantil.

Apesar de a maioria dos entrevistados denunciarem o caráter estressante destas transformações ocorridas da/na universidade, apontam soluções que podem ser caracterizadas como saídas individuais ou microrresistências. Conjuntamente, utilizam-se dos chistes, das piadas, das metáforas em seus depoimentos para explicitar seu trabalho acadêmico atual, em que analisamos como um mecanismo de catarse (FREUD, 1995), na tentativa de superar uma situação insatisfatória. Alguns exemplos dessa estratégia estão presentes nas manifestações que seguem: "Lattes, Lattes meu, existe alguém mais produtivo do que eu" (pesquisador brasileiro); "estamos submetidos ao efeito bonsai" (pesquisador português). Ou ainda nas frases e expressões como "engenharia acadêmica", "linha de montagem de textos", que remetem ao quanto os pesquisadores estão inseridos em um processo 
que poderíamos associar ao taylorismo-fordismo, modelo que se supunha superado neste início de século, e, por fim, no depoimento de outro entrevistado ao afirmar que somos "intelectuais orgânicos do nosso Curriculum". As falas dos entrevistados contêm várias manifestações desse teor e, por sua vez, encontram respaldo na literatura. Conforme Fernández Liria e Serrano García (2009, p. 14), "isso fez com que, para salvar seu emprego e seu salário, os professores começaram a trabalhar mais no markenting do seu currículo que nas suas aulas e em suas pesquisas".

Entre as manifestações dos entrevistados, constatamos tentativas de lidar com essas situações adversas, insatisfatórias, que se refletem no processo de produção do conhecimento e na própria vida extrauniversidade. É como se os pesquisadores procurassem habituar-se, tornar corriqueiro aquilo que no dia a dia é pouco suportável. Poderíamos dizer, com apoio do personagem do clássico conto russo La nada: "qualquer padecimento deixa de o ser quando se converte em um hábito" (ANDRÉIEV, 2009, p. 23).

Entre os entrevistados, não há uma posição contrária ao Sistema de avaliação da PG. É considerada necessária e imprescindível, porém ressaltam que deveria ter uma característica de avaliação formadora. Destaca-se que, para muitos dos pesquisadores entrevistados, a dissertação ou a tese encerrava o período de formação e produção acadêmica. Se a dissertação e/ou a tese eram consideradas o ponto de chegada em termos de investigação e de avaliação, agora não passam de um ritual de passagem entre tantos outros, como é o caso de publicar a própria tese ou artigos e mais artigos. Inclusive detecta-se, a partir destas novas necessidades da carreira, o surgimento de textos e livros que podem ser caracterizados como 'autoajuda acadêmica', pois tem o intuito de preparar os jovens pesquisadores para a sua trajetória acadêmica. Exemplar, neste aspecto, é o livro Germano (2008) - Cómo transformar tu tesis em libro -, experiente editor, que traz uma série de reflexões e indicações para pósgraduandos, incitando-os a publicar e dando-lhe dicas de como canalizar as energias fazendo uma coisa só: a tese em forma de livro.

Pode-se dizer que entre os entrevistados sobressai certo desencanto com o que consideram o desvirtuamento do processo e dos resultados do trabalho universitário. Estes depoimentos entram em rota de colisão com o entendimento de Barreto e Borges (2009, p. 602), apologistas desta nova universidade, ao afirmarem: "É necessário (...) fazer mais e mais rápido". 


\section{Conclusão}

Essa "quebra paradigmática" (KUHN, 1978) a que foram submetidos os Programas de PG avaliados pela CAPES, bem como as mudanças que vêm sendo induzidas pela implementação do Processo de Bolonha, a partir de meados da década de 1990 e princípios do século XXI, provocaram reações diversas entre os envolvidos, que vão da adesão pura e simples às mobilizações e resistências tanto entre o corpo docente quanto entre os pós-graduandos. As resistências, no entanto, podem ser caracterizadas como microrresistênicas, como saídas predominantemente individuais, uma vez que a vinculação da avaliação ao financiamento trouxe como decorrência dificuldades ou até impedimentos de alternativas coletivas, institucionais. Como os organismos de financiamento querem resultado para conceder subvenções, essas manifestações de resistências tornam-se frágeis. O que predomina, efetivamente, é a lógica contábil: "O clima geral, que hoje reina na pesquisa, se caracteriza pelo fato de que o financeiro sobrepôs-se sobre o sentido, e os 'resultados' sobre a pesquisa" (HESS, 2005, p. 63). O próprio processo de avaliação, na perspectiva da formação, perde sentido, uma vez que esta estratégia de avaliar pelo viés do quantitativo faz com que se insira componentes de recompensa e punição, o que descaracteriza o papel da avaliação.

Quanto ao Processo de Bolonha, nos pontos em que se aproxima do modelo CAPES, a resistência in totum ou coletiva também parece estar fora de cogitação. De acordo com Fernández Liria e Serrano Garcia (2009), as comissões encarregadas de implementar o Processo nas universidades, trabalharam, por opção ou sob coação, na adequação à Bolonha sob a "retórica do naufrágio", isto é, dadas as circunstâncias, o que é possível salvar! Seja como for, continuam estes autores, a "via institucional logo se converteu em uma armadilha mortal frente a qual não havia mais alternativa que não fosse dizer sim ou sim a Bolonha, mesmo quando mais se queria dizer não". E, apelando para o chiste, concluem: "Bolonia han sido 'lentejas, que, o las tomas o las dejas"” (p. 25). Em outras palavras, ou se adere incondicionalmente ou se é excluído.

Nossa investigação permitiu constatar que, progressivamente, os Programas e seus respectivos pesquisadores foram acomodando-se às mudanças e à política indutiva da CAPES, bem como às determinações contidas no Processo de Bolonha. Pode-se afirmar que os questionamentos vieram arrefecendo, como se tivéssemos alcançado o "consenso" ou chegado a um "período de ciência normal" (KUHN, 1978). 
Evidentemente, as críticas não deixaram de existir, principalmente na relativização dos números que são apresentados como indicadores do sucesso do(s) Modelo(s) e, em especial, na necessidade de avançar nas estratégias de "qualificação da quantidade".

Ainda na direção das críticas, em recente publicação, Duarte Junior (2010) denomina essa desenfreada proliferação de papers em todas as áreas, apesar da heterogeneidade das ciências, de "papéis podres" (rotten papers), fazendo alusão exatamente à forma como os economistas denominam papéis sem valor que são comercializados nas bolsas de valores. De outra parte, autores como Salles (2010), tendo presente a multiplicação de eventos nos quais uma quantidade cada vez maior de pesquisadores consagrados ou em formação 'desfilam', apresentando dados de suas pesquisas, sem possibilidade de discussões para aprofundamento, alerta para os riscos da consagração de uma nova forma de turismo, denominado de "turismo intelectual".

Sem desconhecer a importância daquilo que se consegue alcançar com esse(s) modelo(s), não há como não se posicionar no sentido de uma vigilância na direção de garantir que não se abandone a preocupação com a formação, com o aprofundamento, com as características e especificidades de áreas com perfis epistemológicos e estratégias metodológicas diferentes e que não podem, sob pena da sua descaracterização, ser submetidas a medidas idênticas. A resistência à heteronomia e aos modelos idênticos para áreas diferentes precisa ser reforçada e as saídas buscadas pela via do coletivo. Caso contrário, os novos managers (AMARAL; MAGALHÃES, 2004) que invadiram e estão dando a direção do ser fazer/universidade, se tornarão hegemônicos.

No tocante à questão da formação, aludida acima, pensamos ser oportuno inserir aqui uma manifestação de Arantes e Arantes (1991), ao fazerem referência à ação e às reflexões do filósofo Ernani Maria Fiori (1914-1985):

Hoje em dia, suplantado pelo fabricante de currículo, pelo profissional que não perde tempo com aluno e produz papers anódinos em escala industrial, o professor é uma espécie em extinção, e, com ele, vai-se perdendo, lembra Antonio Candido, a capacidade de transmitir e configurar conhecimento, "não apenas para que o educando o possua, mas para que, através dele, se oriente melhor na sociedade e, em geral, na vida”. Mas, no final das contas, a filosofia não se resume a isto, saber orientar-se através do pensamento? (p. 1). 
Se admitimos que houve uma "quebra paradigmática", é pelo próprio autor que muito se dedicou ao estudo dos modelos que é apontada uma saída:

A ciência normal desorienta-se, seguidamente. E quando isto ocorre - isto é, quando os membros da profissão não podem mais esquivar-se das anomalias que subvertem a tradição existente da prática científica - então começam as investigações extraordinárias que finalmente conduzem a profissão a um novo conjunto de compromissos, a uma nova base para a prática da ciência. (KUHN, 1978, p. 25).

Enfim, com base em nossas pesquisas e nas diferentes reflexões sobre o ensino superior, em especial a pós-graduação e a pesquisa no Brasil, bem como nas discussões que começam a ganhar cada vez mais espaço nos eventos científicos, podemos afirmar que a PG está marcada pela "atenção imediata ao imediato" (BOURDIEU, 1984), que isola o momento crítico e acentua a diferenciação, quando se deveria estar lutando para "escapar à alternativa da 'ciência pura', totalmente livre de qualquer necessidade social, e da 'ciência escrava', sujeita a todas as demandas político-econômicas" (BOURDIEU, 2004, p. 21); quando se deveria estar reforçando um movimento de organização e de adensamento das estratégias de resistência a essa forma de fazer pesquisa e de produzir ciência, cujos resultados conspiram contra a qualidade, seja do conhecimento produzido, seja da vida/trabalho dos envolvidos com a PG. Mas poderíamos ir mais longe, perguntando se se trata da promoção de um "modo de regulação institucional assegurada por um "Estado avaliador"' (POUPEAU, 2003), que reduz as reformas, necessárias tanto à escola quanto à pesquisa, aos critérios da eficácia, da competitividade, das competências; uma lógica que responde unicamente a demandas individuais de educação coerentes com uma cultura de mercado.

\section{Referências}

ADELMAN, C. The Bologna Club: what U.S. Higher Education can learn from a decade of european reconstruction. [S.1.]: Institute for Higher Education Policy, 2008.

AMARAL, A.; MAGALHÃES, A. Epidemiology and the Bologna saga. Kluwer Academic Publishers, [S.1.], n. 48, p. 79-100, 2004. 
ANDRÉIEV, L. La nada: cuentos breves para leer en el bus. 14 ed. Barcelona: Verticales de bolsillo, 2009.

ARANTES, O. B; ARANTES, P. E. Apresentação. In: FIORI, E. M. Textos escolhidos: v. 2.: Educação e Política. Porto Alegre: L\&PM, 1991.

BARRETO, F. C. S.; BORGES, M. N. Novas políticas de apoio à pós-graduação: o caso FAPEMIG-CAPES. Ensaio: aval. pol. públ. educ. Rio de Janeiro, v. 17, n. 65 , p. 599-612, out.-dez., 2009.

BIANCHETTI, L. Os dilemas do coordenador de programa de pós-graduação: Entre o burocrático-administrativo e o acadêmico-pedagógico. In: BIANCHETTI, L; SGUISSARDI, V. Dilemas da pós-graduação em educação: gestão e avaliação. Campinas: Autores Associados, 2009a.

30 anos do Colégio Brasileiro de Ciências do Esporte: Os desafios para uma Associação Científica e os dilemas dos intelectuais institucionalizados. Revista Brasileira de Ciências do Esporte. Campinas/Autores Associados, v. 30, p.13 - 30, 2009b.

O Processo de Bolonha e a intensificação do trabalho na universidade: entrevista com Josep M. Blanch. Educação \& Sociedade, Campinas, v. 31, n. 110, p. 263-286, 2010.

BINDÉ, J. (Coord.). Rumo às sociedades do conhecimento: relatório mundial da UNESCO. Lisboa: Instituto Piaget, 2007.

BOURDIEU, P. Homo academicus. Paris: Minuit, 1984.

Os usos sociais da ciência: por uma sociologia clínica do campo científico. São Paulo: Editora UNESP, 2004.

CARRERAS GARCÍA, J. et al. Euro-universidad: mito y realidad del processo de Bolonia. Barcelona: Icária, 2006.

CHAUÍ, M. A universidade pública sob nova perspectiva. Revista Brasileira de Educação. Rio de Janeiro, n. 24, p. 5-15, set./out./nov./dez. 2003. 
CURY, C.R.J. Graduação/Pós-Graduação: a busca de uma relação virtuosa. Educação e Sociedade, Campinas, v. 25, n. 88, p. 777-793, 2004.

Quadragésimo ano do parecer CFE n. 977/65. Revista Brasileira de Educação, Rio de Janeiro, n. 30, p. 7 -22, set./out./nov./dez. 2005.

DIAS SOBRINHO, J. O processo de Bolonha. In: PEREIRA, E. M. de A.; ALMEIDA, M. de L. P. (Org.). Universidade contemporânea: políticas do processo de Bolonha. Campinas: Mercado de Letras, 2009.

DUARTE JUNIOR, J.F. The rotten papers (ou adiós que yo me voy). In: DUARTE JUNIOR, J. F. A montanha e o videogame: escritos sobre educação. Campinas, SP: Papirus, 2010.

FERNÁNDEZ LIRIA, C.; SERRANO GARCÍA, C. El plan Bolonia. Madrid: Catarata, 2009.

FREUD, S. Os chistes e sua relação com o inconsciente. In: Obras Completas. Rio de Janeiro: Imago, 1995.

GERMANO, W. Cómo transformar tu tesis en libro. Madrid: Siglo XXI, 2008.

HESS, R. Produzir sua obra: o momento da tese. Brasília: Liber Livro, 2005.

JACOBY, R. O fim da utopia: política e cultura na era da apatia. Rio de Janeiro: Record, 2001.

KUENZER, A. Z.; MORAES, M. C. M. Temas e tramas na pós-graduação em educação. Educação \& Sociedade, Campinas, v. 26, n. 93, p. 1341-1363, set./ dez. 2005.

KUHN, T. S. A estrutura das revoluções cientificas. 2 ed. São Paulo: Perspectiva, 1978.

LIMA, L. et al. O processo de Bolonha, a avaliação da educação superior e algumas considerações sobre a universidade nova. Avaliação, Campinas; Sorocaba, v. 13, n. 1, p. 7-36, mar. 2008. 
LÜDKE, M. Influências cruzadas na constituição e na expansão do sistema de pós-graduação stricto sensu em educação no Brasil. Revista Brasileira de Educação, Rio de Janeiro, n. 30, p. 117-123, set./dez. 2005.

MENDONÇA, A. W. P. C. A pós-graduação como estratégia de reconstrução da universidade brasileira. Educar em Revista, Curitiba, n. 21, p. 289-308, 2003.

MORAES, M. C. M. O processo de Bolonha vis a vis a globalização de um modelo de ensino superior. Perspectiva: Revista do Centro de Ciências da Educação, Florianópolis, v. 24, n. 1, p. 187-204, jan/jun. 2006.

MOROSINI, M. C. Internacionalização da educação superior no Brasil pós-LDB: o impacto das sociedades tecnologicamente avançadas. In: BITTAR, M. et al. Educação superior no Brasil: 10 anos pós-LDB. Brasília: INEP, 2008.

NERAD, M.; HEGGELUND, M. (Ed.). Toward a Global PhD? : forces \& forms in doctoral education worldwide. Seattle; London: University of Washington Press, 2008.

NÓVOA, A. Modelos de análise em educação comparada: o campo e a carta. In: SOUZA, D. B. de. \& MARTÍNEZ, S.A. (Org.). Educação comparada: rotas de além-mar. São Paulo: Xamã, 2009.

PARASKEVA, J.M. (Org.). Capitalismo Académico. Mangualde, PT: Edições Pedago, 2009.

POUPEAU, F. Une sociologie d'État : l'ecole et ses experts en france. Paris: Raisons d'Agir, 2003.

RIGHETTI, S. Artimanhas inflam produção científica. Folha de S. Paulo, São Paulo, Caderno A, p. 19, jul. 2010.

RIBEIRO, D. A universidade necessária. São Paulo: P\&T, 1969.

RIBEIRO, R. J. Doctoral Education in Africa, South America, and Mexico. Brazil. In: NERAD, M.; HEGGELUND, M. (Ed.). Toward a Global PhD?: forces \& forms in doctoral education worldwide. Seattle; London: University of Washington Press, 2008. p. 131-145. 
ROBERTSON, S. O processo de Bolonha da Europa torna-se global: modelo, mercado, mobilidade, força intelectual ou estratégia para construção do Estado? Revista Brasileira de Educação, Campinas, v. 14, n. 42, p. 407422, set./dez. 2009.

RUIZ, R. El Proceso de Bologna, cuatro años después (Uma evaluación Del Área Europea de Educación Superior). Pró-Posições, Campinas, v. 15, n. 3, p. 21-36, set./dez. 2004.

SALLES, J. C. Notas sobre a filosofia no Brasil. Cult: Revista Brasileira de Cultura, Rio de Janeiro, ano 13, v. 151, p. 71-74, 2010.

SAVIANI, D. A pós-graduação em educação no Brasil: pensando o problema da orientação. In: BIANCHETTI, L.; MACHADO, A.M.N. (Org.). A bússola do escrever: desafios e estratégias na orientação e escrita de teses e dissertações. 3 ed. São Paulo: Cortez, 2012.

SERRALHEIRO, J. (Org.). O processo de Bolonha e a formação dos educadores e professores portugueses. Porto: Profedições, 2005.

SGUISSARDI, V. Rumo à universidade mundial - E a universidade será feita à sua imagem e semelhança. Serie Documental: textos para discussão, Brasília, DF, v. 10, n. 20, p. 7-28, 2005.

A avaliação defensiva no "Modelo CAPES de Avaliação": é possível conciliar avaliação educativa com processos de regulação e controle do Estado? In: BIANCHETTI, L.; SGUISSARDI, V. (Org.). Dilemas da pós-graduação: gestão e avaliação. Campinas, SP: Autores Associados, 2009.

SGUISSARDI, V; SILVA JUNIOR, J. R. Trabalho intensificado nas federais: pós-graduação e produtivismo acadêmico. São Paulo: Xamã, 2009.

SIMÃO, J. V. et al. A ambição para a excelência: a oportunidade de Bolonha. Lisboa: Gradiva, 2005.

SLAUGHTER, S.; RHOADES, G. Academic capitalism and the new economy: markets, state and higher education. Baltimore: John Hopkins University Press, 2004. 
SOKAL, A.; BRICMONT, J. Imposturas intelectuais: o abuso da ciência pelos filósofos pós-modernos. Rio de Janeiro e São Paulo: Record, 1999.

SOUZA, D. B. de; MARTÍNEZ, S.A. (Org.). Educação comparada: rotas de além-mar. São Paulo: Xamã, 2009.

WATERS, L. Inimigos da esperança: publicar, perecer e o eclipse da erudição. São Paulo: Editora UNESP, 2006.

WEBER, M. Ciência e politica duas vocações. São Paulo: Cultrix, 4 ed. s/d.

Recebido em: 06/03/2012

Aceito para publicação em: 02/09/2013 


\section{Academic "productivism" and consequences for the living and working conditions of Brazilian and European researchers}

\section{Abstract}

A version of this paper was presented at the 25th Brazilian Symposium and the 2nd Ibero-American Congress of Education Policy and Administration, 2011, at PUC/ SP. It is the result of a study with 74 program coordinators and advisors linked to graduate programs evaluated by CAPES and with 16 researchers at universities in the European Union, after their adhesion to the Bologna Agreement. It presents these professionals' comments about the recent changes to which the universities have been submitted, transformations which led to what has been called "Academic Productivism," with consequences for the quality of intellectual and academic work and for the institutional and personal life of the professionals dedicated to teaching and research in undergraduate and graduate studies.

Keywords: "Productivism". Work and Education. CAPES. Bologna Process.

\section{El productivismo académico y sus consecuencias - las condiciones de vida y del trabajo de investigadores brasileños y europeos}

\section{Resumen}

Una versión de este trabajo fue presentada en el $25^{\circ}$ Simposio Brasileño y en el $2^{\circ}$ Congreso Iberoamericano de Política y Administración de la Educación, 2011, en la PUC/SP-Pontificia Universidad Católica de San Pablo. Es el resultado de una investigación con 74 Coordinadores de Programas y Profesores que guían las investigaciones y que están vinculados a los Programas de Posgrado stricto sensu evaluados por la CAPES y con 16 investigadores vinculados a universidades de la Unión Europea, después de la adhesión de estas instituciones al "Pacto de Bolonia". Presenta las manifestaciones de estos profesionales sobre los cambios recientes a los cuales las universidades se sometieron, transformaciones que, en su proceso y resultado, han dado lugar a lo que se conoce como "Productivismo Académico", con consecuencias en la calidad de las producciones intelectuales/ académicas y en la vida institucional y personal de los profesionales dedicados a la docencia y a la investigación en los Programas de graduación y posgrado. Palabras-clave: Productivismo. Trabajo y Educación. CAPES. Proceso de Bolonia. 